\title{
BIBLIOTECA VIRTUAL DO MEIO AMBIENTE: SOCIALIZAÇÃO E APRENDIZAGEM ACERCA DO ESPAÇO DA BAIXADA FLUMINENSE
}

\author{
1Prof. Dra. Simone Fadel - simonefadel@hotmail.com \\ ²Gabriel de Lima Souza - gabriel.geo2010@gmail.com \\ Cibelly Alves Gemmal - cibellygemmal@hotmail.com \\ Patrícia Carvalho - patriciasouza_carvalho@hotmail.com
}

\begin{abstract}
Resumo
Esse artigo tem o objetivo de relatar a experiência do projeto Biblioteca Virtual do Meio Ambiente, site que propõe a divulgação científica de informações sobre a Baixada Fluminense, região do Estado do Rio de Janeiro, Brasil. Graduandos de Geografia da Faculdade de Educação da Baixada Fluminense participam do projeto na tentativa de democratizar os saberes do meio ambiente da região através de caixas de informações sobre Educação Ambiental, Justiça Ambiental, História Ambiental, Dinâmica Ambiental e Sistemas Naturais. As discussões do projeto envolvem a necessidade de pensarmos numa educação ambiental crítica que considera que os problemas ambientais são consequências da estrutura de organização social desigual além de que esses problemas são distribuídos desigualmente entre as classes sociais existentes. Nesse sentido, acreditamos que este projeto contribui para a discussão da Educação Geográfica, visto que ao elaborar os textos que preenchem as caixas, os graduandos mobilizam a todo momento bibliografias e debates de diversos conteúdos da Geografia.
\end{abstract}

Palavras-chave: Geografia; Biblioteca Virtual; Baixada Fluminense; Educação Ambiental Crítica.

\footnotetext{
${ }^{1}$ Professora Adjunta da Universidade do Estado do Rio de Janeiro e Pesquisadora do Núcleo Interdisciplinar de Estudos do Espaço da Baixada Fluminense (NIESBF)

2 Aluno do Programa de Pós Graduação do Departamento de Geografia da Pontifícia Universidade Católica do Rio de Janeiro - PUC-Rio - Bolsista da CAPES
} 


\section{Introdução}

Este trabalho tem como objetivo contribuir com a discussão da educação geográfica a partir do enfoque da educação ambiental. Trata-se de um trabalho desenvolvido junto a graduandos do curso de licenciatura em Geografia com ênfase no meio ambiente da Universidade do Estado do Rio de Janeiro. Embora a questão ambiental se apresente cada vez mais como uma questão central na análise do mundo atual, trabalhos que possam oferecer um suporte para análise do ambiente local ainda estão aquém da problemática ambiental e das mudanças que ocorreram no contexto político ambiental no Mundo e no Brasil nas últimas décadas. Questões como preservação ambiental, justiça ambiental, educação ambiental, gestão dos recursos naturais, participação e controle social estão postos em diferentes pautas seja no que se refere às instituições públicas, à sociedade civil ou às instâncias que articulam o Estado e a Sociedade Civil, como os Conselhos de meio ambiente.

Mesmo que de forma ampla, o quadro apresentado acima aponta a necessidade de que a Universidade proporcione no âmbito da formação de professores, em especial de Geografia, a possibilidade de construção de conhecimentos e canais de democratização da informação oferecendo suporte para o aperfeiçoamento das estratégias e mecanismos que visem ações ecologicamente corretas, socialmente justas e culturalmente aceitas. Nesta perspectiva, iniciamos em 2007, o projeto de extensão, intitulado Biblioteca Virtual do Meio Ambiente da Baixada Fluminense. O projeto se constituiu inicialmente como um site de divulgação científica (http://www.bvambientebf.ueri.br/) que tem como público alvo privilegiado os educadores da região, visando contribuir para a superação da escassez de fontes sobre o ambiente local, visto que a região é vista de forma negativa, principalmente, devido à poluição dos rios, depósitos de lixo, fábricas clandestinas.

Embora os docentes, no processo de educação continuada, se constituam, como um público-alvo privilegiado do trabalho, a utilização desta ferramenta como recurso pedagógico no curso de graduação, através da disciplina Educação Ambiental, e, principalmente, a participação de graduandos em projetos de pesquisa e extensão tem demonstrado uma grande eficácia na sensibilização da temática socioambiental na formação dos licenciados. Atualmente, o projeto é composto de diferentes ferramentas. Além da permanência do site original, disponibilizamos um site voltado para o público infanto- juvenil (http://www.bvjovem.ueri.br/), além de um blog para a divulgação dos conflitos socioambientais locais (http://bvemdia.blogspot.com.br/). Todas estas ferramentas são construídas por graduandos de Geografia e tem como desafio a articulação da educação ambiental com Educação Geográfica em todos os níveis de ensino.

\section{Concretizando uma ideia: o processo de criação da Biblioteca Virtual}

A Biblioteca Virtual do Meio Ambiente da Baixada Fluminense (BV) foi criada tendo como público-alvo privilegiado os educadores da região. O desenvolvimento de trabalhos no campo da Educação Ambiental teve início no projeto de pesquisa Núcleo de Educação Continuada (NEC) em 1996, mas foi somente em 2007 que a BV se consolidou como um projeto próprio de extensão universitária no campo da divulgação científica, pioneiro na região da Baixada Fluminense. Posteriormente, a BV estabeleceu outras parcerias, como 
o apoio financeiro da Fundação Carlos Chagas de Amparo à Pesquisa do Estado do Rio de Janeiro (FAPERJ) ${ }^{1}$ e a parceria interna com o Núcleo Interdisciplinar de Estudos do Espaço da Baixada Fluminense (NIESBF), cujo objetivo foi o de desenvolvimento e difusão do conhecimento produzido na unidade, em especial junto ao curso de Licenciatura em Geografia. O foco da BV na Baixada Fluminense é resultado da experiência desenvolvida junto aos docentes do Ensino Fundamental e Médio, que nos apresentou a questão da escassez de fontes sobre o ambiente local e uma perspectiva tradicional sobre os chamados problemas ambientais.

A partir da experiência com a Educação Continuada, partimos para a execução do projeto visando já na formação inicial dos professores de Geografia propiciar um meio de elaboração textual utilizando-se dos conceitos próprios da Geografia no entendimento dos temas presentes nas caixas de informação da BV. Assim, os conceitos de espaço, território, paisagem se construíram como categorias de análise fundamentais para 0 desvelamento dos conflitos socioambientais locais. Espera- se que com essa prática 0 graduando perceba-se como elaborador de conhecimentos que estarão disponíveis, neste caso na internet, e não meros reprodutores de saberes sejam os presentes nos livros didáticos ou os mais "modernos" presentes nos inúmeros downloads realizados.

Desta forma, a relação entre Geografia e o ensino se apresenta como um instrumento da própria construção de um docente autônomo e crítico, superando a realidade apresentada por Braga, quando afirma que:

\begin{abstract}
$\mathrm{Na}$ ausência de uma fundamentação clara e segura de como ensinar uma geografia crítica os professores optam, geralmente ou por permanecerem ensinando a geografia que aprenderam quando alunos, mesmo que insatisfeitos ou por mesclarem esse ensino com algumas práticas por eles traduzidas das atuais tendências (BRAGA, 2006, p. 55)
\end{abstract}

Destaca-se que a Baixada Fluminense é um espaço caracterizado pela consolidação de inúmeras injustiças ambientais resultantes do modelo de desenvolvimento baseado no capitalismo e, portanto consequentes da estrutura de organização social desigual. Ao contrário da naturalização dos chamados "problemas ambientais", procura-se apontar que a poluição dos rios locais, a falta de água e outras tantas questões socioambientais que envolvem a região não são democráticas. Existindo, portanto, populações vulneráveis as consequências da ocupação predatória. A região é composta, inclusive, por comunidades tradicionais como os pescadores artesanais que estão submetidos a enfrentar, por exemplo, os resíduos de indústrias petroquímicas que se aglomeram no entorno da Baía de Guanabara.

Neste sentido, o conceito de justiça ambiental está presente no desenvolvimento do trabalho, entendendo-se que refere-se "aos princípios que asseguram que nenhum grupo de pessoas, sejam grupos étnicos, raciais ou de classe, suporte uma parcela desproporcional degradação do espaço coletivo" (ACSELRAD, HERCULANO, PÁDUA, 2004). A desigual distribuição dos riscos ambientais pelas classes sociais é uma consequência da economia capitalista, onde os benefícios gerados pela produção de mercadorias e de serviços se concentram nas camadas mais altas da sociedade, enquanto esses riscos ambientais concentram-se nas camadas mais baixas da sociedade. Os integrantes dessas camadas mais altas, por exemplo, tem condições de

\footnotetext{
${ }^{1} \mathrm{O}$ apoio da FAPERJ se deu no financiamento da pesquisa Meio Ambiente e Saneamento (Edital Primeiros Projetos/2006), que auxiliou no processo de criação da Biblioteca Virtual. Após seu lançamento na web, a BV foi apresentada na Semana de Meio Ambiente da UERJ (2006) e selecionada como um dez trabalhos destacados para compor a publicação especial do evento.
} 
usar a riqueza oriunda da produção para morar em áreas ambientalmente seguras. Desta forma, as injustiças ambientais do espaço da Baixada Fluminense não devem ser naturalizadas - são consequências do modelo de desenvolvimento desigual e de um pensamento dominante fragmentado que afasta as questões ambientais das injustiças sociais.

Destaca-se, também, que a Baixada Fluminense possui em seu território diversas áreas de proteção ambiental (Reserva de Tinguá, Parque Municipal da Taquara, Área de Proteção Ambiental de Guapimirim, entre outras) sem contar que, segundo dados da Secretaria de Meio ambiente de Nova Iguaçu, mais da metade deste município se constitui como área preservada, apesar de não possuir uma política pública consolidada para a efetivação das mesmas. Muitas Unidades de Conservação locais são fundamentais para a formação de uma área de Mata Atlântica remanescente contínua, conhecida como Mosaico Central Fluminense. ${ }^{2}$

Destarte, com o objetivo de promover o acesso online eficiente e democrático às informações relevantes e atualizadas sobre o meio ambiente da Baixada Fluminense, o projeto da BV acabou por se tornar um canal fundamental de democratização do saber sobre o meio ambiente, produzido pelas pesquisas realizadas na referida unidade acadêmica contendo professores do Departamento de Geografia pertencentes ao Núcleo Interdisciplinar de Estudos da baixada Fluminense (NIESBF). Por essa razão, a BV é composta por caixas de informações que se constituem como campos temáticos de investigação do NIESBF: História Ambiental, Educação Ambiental, Dinâmica Ambiental e Sistemas Naturais (Sistema Nacional de Unidades de Conservação).

A caixa de História Ambiental está dividida em três sub-tópicos independentes: Os Viajantes; As estradas de Ferro e as Comissões de Saneamento até o período de 1930. Nesta caixa procuramos também apresentar informações biográficas básicas sobre os atores sociais fundamentais que constituíram cada temática apresentada nos sub-tópicos. A caixa referente à Educação Ambiental buscou até o momento apresentar os marcos históricos de constituição da Educação Ambiental no Brasil e no mundo, assim como seus princípios e métodos. A navegação por essa caixa permite ao usuário conhecer diversos documentos e tratados referentes às diversas conferências internacionais, bem como os principais desafios ambientais postos atualmente. É valido ressaltar que o tema da Justiça ambiental, bem como, a divulgação dos movimentos sociais locais que abordam os conflitos socioambientais locais se constitui como sub-tópico desta caixa.

A caixa dos Sistemas Naturais tem como objetivo apresentar dados, fontes, literatura técnico-científico que auxilie na ruptura da ideia presente no senso comum de que a Baixada Fluminense se constitui apenas como um local degradado. No entanto, os ecossistemas da região ainda carecem de estudos por parte das instituições científicas. A diversidade ambiental local, por exemplo, incluindo as áreas já preservadas, é um campo pouco explorado. Assim, ainda são escassos os levantamentos da flora e da fauna, o mapeamento de áreas de Manguezal e Mata Atlântica existente nas Unidades de conservação local ou em áreas remanescentes. Destaca-se, também, a divulgação do Mosaico Central Fluminense e as Unidades de Conservação da região. Por fim na caixa de Dinâmica Ambiental, apresentamos as mudanças na paisagem frente à ocupação do espaço urbano que tem se dado de maneira desordenada, subindo em direção às

\footnotetext{
${ }^{2}$ Sobre Mosaico Central Fluminense ver www.mosaicocentral.org.br
} 
encostas e ao longo dos canais fluviais, causando riscos à sociedade como um todo, desde enchentes aos deslizamentos, crescentes na região.

Esperou-se, ainda, que além da socialização do conhecimento resultado das pesquisas desenvolvidas sobre a História Ambiental local, também fosse disponibilizado através do acesso online produções científicas completas ou links que permitam ao usuário encontrar um acervo digital, constituído de uma verdadeira rede que interliga desde acervos locais a bibliotecas virtuais mais amplas, sítios do Ministério do Meio Ambiente, Ministério da Ciência e Tecnologia, dentre outros. Podemos destacar as monografias elaboradas por alunos da unidade cujo objeto de estudo é construído a partir do ambiente local ou ainda acesso a outras fontes como a Revista Pilares da História ${ }^{3}$ e os artigos de diferentes épocas sobre a Baixada Fluminense, publicados na Revista Brasileira de Geografia (RBG) ${ }^{4}$.

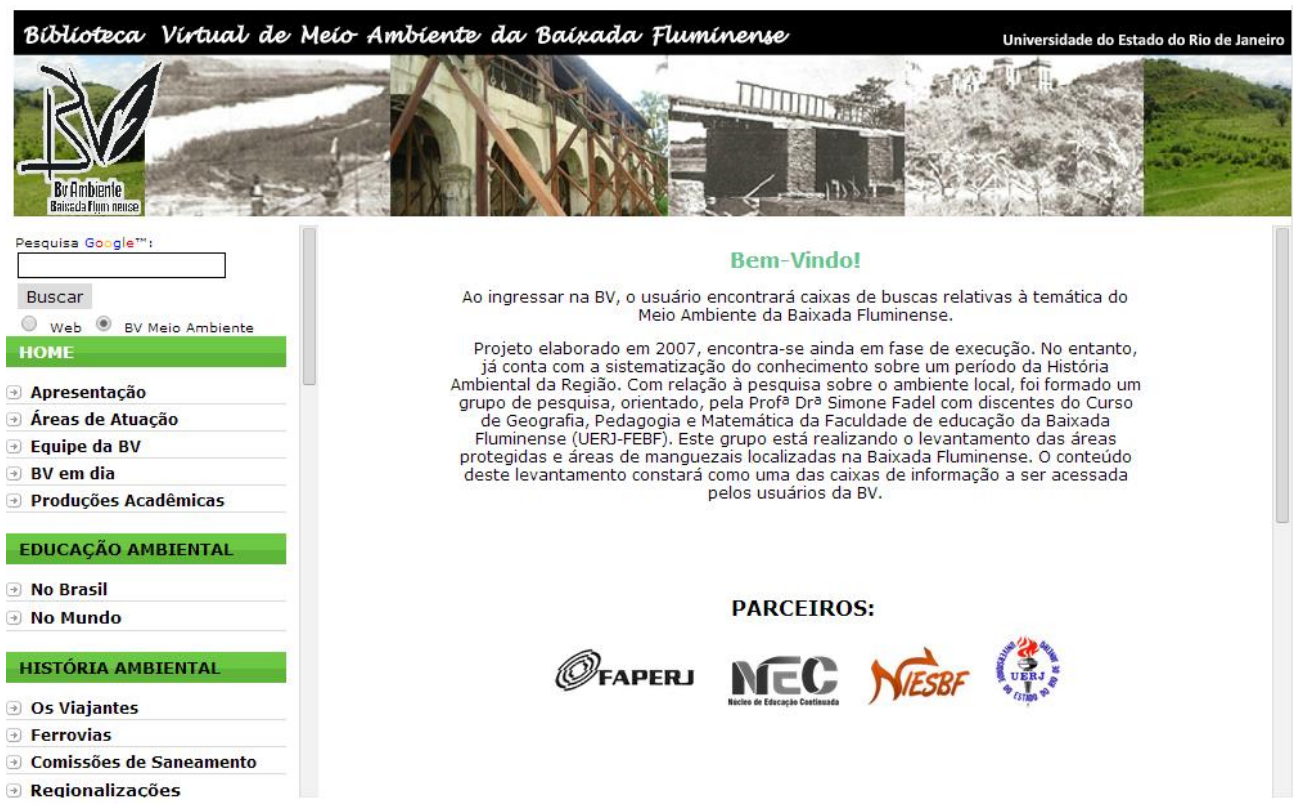

Figura 1: Página Inicial da Biblioteca Virtual do Meio Ambiente da Baixada Fluminense (www.bvambientebf.uerj.br).

\section{Possibilitando Interfaces: meios de divulgação para a Biblioteca Virtual}

É notório que as Tecnologias da Informação e Comunicação (TIC's) possuem atualmente grande apelo e inserção social (KENSKI, 2007). Além disso, com o surgimento tão acelerado de novas tecnologias, bem como a utilização maciça da internet e

\footnotetext{
${ }^{3}$ Publicação conjunta do Instituto Histórico da Casa Legislativa e a Câmara Municipal de Duque de Caxias.

${ }^{4}$ A Revista Brasileira de Geografia (RBG) teve suas primeiras edições lançadas em 1939 pelo Instituto Brasileiro de Geografia e Estatística (IBGE) com conteúdo do ramo da geociência e de alguns estudos metodológicos. A BV fez um trabalho minucioso de seleção de alguns dos artigos lançados entre 1939 e 2005, cujas temáticas eram relacionadas à Baixada Fluminense, disponibilizando esses artigos, dos quais as edições completas encontram-se também na web, através da Biblioteca Virtual do IBGE.
} 
ferramentas de comunicação baseadas na web 2.0, torna-se de interessante e nítida a possibilidade de se direcionar essas tecnologias para a divulgação do conhecimento na internet. A internet é um espaço democrático que possibilita o circular de um volume considerável de informações. O ciberespaço rompe com o esquema tradicional emissormensagem-receptor, fazendo com que todos produzam o conhecimento, sendo autores e coautores das mensagens, do conhecimento.

Ante essas questões, foi-se pensado em estratégias baseadas na utilização de TIC's para promover a divulgação de produções científicas e de informações relacionadas ao eixo temático da Biblioteca Virtual de Meio Ambiente da Baixada Fluminense. $O$ principal intuito é criar novas interfaces, novas pontes entre a BV e seu público-alvo.

Para tanto, foi feito uso de várias tecnologias disponíveis atualmente para criar essas novas interfaces, novas ligações, não só com a comunidade acadêmica e científica, mas também levar esses questionamentos para o âmbito educacional e para a sociedade. Uma das formas de divulgação que criamos foi a BV em Dia (http://bvemdia.blospot.com.br), blog cuja atuação é uma forma de sistematizar e resumir as informações que dispomos no site da BV, disponibilizando informações acerca da própria BV e outros assuntos relacionados ao principal eixo da Biblioteca Virtual, ou seja, o Meio Ambiente da Baixada Fluminense. Trata-se ainda de um espaço cuja publicação periódica permite-nos incluir notícias e acompanhamento das principais atividades acadêmicas e socioambientais locais. Ao todo, já foram produzidas mais de 50 edições com mais de 8.000 acessos tendo como alguns temas abordados: Fórum dos Afetados pela Indústria do Petróleo e Petroquímica nas cercanias da Baía de Guanabara; Associação da Feira da Roça de Nova Iguaçu (A.F.E.R.N.I); Infestação de Caramujos Africanos em São João de Meriti; IV Conferência Nacional Infanto-juvenil pelo Meio Ambiente - CNIJMA; Paralisação de obras do Comperj; entre outros.

Em paralelo à BV Em Dia, tornou-se interessante criar outros mecanismos de divulgação científica através também de redes sociais, que, vale ressaltar, são responsáveis pelo maior índice de acessos à internet no mundo. Foram criadas, portanto, páginas denominadas fanpages na rede social Facebook ${ }^{5}$ tanto da Biblioteca Virtual do Meio Ambiente da Baixada Fluminense, quanto do Núcleo Interdisciplinar de Estudos do Espaço da Baixada Fluminense (NIESBF). O principal intuito com isso é favorecer o compartilhamento de conhecimento e produções científicas, além de promover de forma interativa e dinâmica, vários debates ligados aos eixos temáticos da BV e do NIESBF.

Em tão pouco tempo, foi possível ver um avanço considerável no circular de informações que dispomos na web, além de uma participação maior e mais ativa dos alunos da própria Faculdade de Educação da Baixada Fluminense (FEBF/UERJ) perante as produções do núcleo de pesquisa da referida universidade. Ou seja, com o poder das novas tecnologias, são criadas relações entre os estudos e pesquisas do NIESBF e da BV com os alunos da própria instituição de ensino que abriga tal projeto e núcleo de pesquisa ${ }^{6}$.

Nos anos seguintes à primeira edição da BV, novas pesquisas foram sendo desenvolvidas. Em 2011, dentro da linha de pesquisa História Ambiental, desenvolveu-se

\footnotetext{
${ }^{5}$ Ver http://www.facebook.com/bvambientebf

${ }^{6}$ A Biblioteca Virtual junto ao Núcleo de Pesquisa NIESBF conta ainda hoje com a presença de diversas modalidades de bolsas acadêmicas, dentre as quais destacam-se: Bolsa de Iniciação Científica, Estágio Interno Complementar, Iniciação à Docência e Extensão.
} 
um projeto de busca por uma melhor compreensão da evolução histórico-ambiental do Parque Natural Municipal da Taquara, localizado no município de Duque de Caxias, no Rio de Janeiro. A pesquisa se deu através de fontes primárias e secundárias, além de entrevistas com os principais atores sociais associados ao parque, com o intuito de acrescentar maiores dados à caixa de informações sobre a História Ambiental da BV ${ }^{7}$.

Também em 2011, iniciou-se um estudo mais minucioso acerca dos manguezais da região em especial no município de Magé $^{8}$. O Manguezal, conhecido por sua complexidade e importância como o berçário de algumas espécies aquáticas e até terrestres, é um ecossistema de transição entre os ambientes terrestres e marinhos, e pode ser encontrado em muitas partes do planeta. São localizados inicialmente em áreas costeiras das regiões de clima tropicais e subtropicais (LACERDA, 2002). No Brasil, o ecossistema encontra-se ao longo de sua costa e apesar de ser protegido como Área de Proteção Permanente (APP) ${ }^{9}$, vem sofrendo intensos impactos resultantes de processos de ocupação e interesses socioeconômicos (FADEL, SOUZA e FERNANDES, 2012). Para a BV, este estudo tornou-se de grande importância, visto que da região da Baía de Guanabara, o recôncavo, área cujos municípios pertencem à Baixada Fluminense, apresenta a maior quantidade de área contínua com remanescentes de manguezais de toda a região Sudeste, concentrados principalmente na Área de Proteção Ambiental de Guapimirim, e no município de Magé, com algumas manchas dispersas na divisa com o município de Duque de Caxias.

É justamente no município de Magé que se encontram os manguezais mais impactados, devido à localização do município ao fundo da Baía, o que faz com que a região receba diariamente o lixo lançado na Baía de Guanabara, assim como esgoto doméstico e a contaminação química da Refinaria de Petróleo em Duque de Caxias (REDUC). Diante desses impactos ambientais, o município de Magé tem sido palco de ações que tentam mudar este quadro, dentre as quais podemos destacar um projeto de reflorestamento $^{10}$ e as reivindicações de pescadores representados pela Associação Homens do Mar (AHOMAR). Os movimentos dos pescadores buscam maior liberdade nas áreas das quais tiram seu sustento, tentado impedir a entrada de empresas que contaminam as águas e os peixes dos mares nos quais trabalham.

Esse contato maior com as dinâmicas do ecossistema manguezal, os movimentos sociais dos pescadores e a análise dos remanescentes do bioma Mata Atlântica no Parque Municipal da Taquara, permitiu uma ampliação das temáticas nas caixas de informações da BV, assim como divulgações em suas respectivas interfaces. Foi também nesse momento, que uma nova interface surgia na composição da BV, uma interface que embora mantivesse o objetivo geral da BV, buscava avançar para um público diferenciado e que exigiria uma linguagem própria: o público infanto-juvenil. Foi então lançado o

\footnotetext{
${ }^{7}$ A etapa inicial deste trabalho foi apresentado no 50 Encontro da ANPUH realizado em São Paulo, 2011.

${ }^{8}$ Esta etapa inicial do trabalho foi apresentada no V Sapis - Seminário de Áreas Protegidas e Inclusão Social, que ocorreu na UFAM, em Manaus, 2011.

${ }^{9}$ Lei 4.771 de 15 de setembro de 1965 do Código Florestal Brasileiro e Resolução CONAMA N. 369 de 28 de março de 2006.

${ }^{10}$ Desde 2001, ocorre em Magé um Projeto de Reflorestamento de manguezais numa área muito marcada pela poluição e degradação ambiental. Como iniciativa da ONG Fundação OndAzul, o projeto Mangue Vivo, já possui resultados positivos dentre os quais podemos destacar os 12 hectares já recuperados com cerca de 38 mil mudas de mangue plantadas. Para mais informações, acessar o site do Projeto Mangue Vivo http://www.ondazul.org.br/sec_projetos_popup.php?id=16\&sec=projeto
} 
desafio de uma ampliação da Biblioteca Virtual para este público em questão, nascia assim a BV Jovem.

\section{Experimentando novos rumos: a experiência com a Biblioteca Virtual Jovem}

O processo de construção da Biblioteca Virtual Jovem se deu em etapas, visto que tudo era muito novo para um projeto que se consolidara como era o caso da BV. Primeiramente, foram feitas algumas considerações acerca da estrutura digital da Biblioteca Virtual, ou seja, de que forma esta seria apresentada, tendo em vista atrair o novo público alvo: estudantes, crianças e jovens. A ideia geral foi construí-la como um espaço interativo e dinâmico articulando textos, jogos, vídeos e figuras a partir de dois caminhos: o informativo e o interativo.

No ano de 2012, a BV recebeu novos aportes da FAPERJ para viabilizar a sua ampliação com a criação da $1^{\text {a }}$ Edição da BV Jovem. Esta edição priorizou os conhecimentos do bioma do mangue e da Mata Atlântica, tendo em vista as condições socioambientais dos mesmos. Pretendeu-se visar acessibilidade, interatividade e a realidade vivida pelo público infanto-juvenil que a visitasse. Para que isso fosse concretizado, o contato com escolas locais num primeiro momento foi primordial a fim de se descobrir junto às crianças, que informações seriam mais relevantes e mereceriam estar presentes nos materiais digitais.

Num dos primeiros contatos com escolas locais, foram realizadas oficinas cujos resultados dariam caminhos nas decisões quanto ao que incluir, e ao que dar mais ênfase em todo o desenvolvimento da BV Jovem. Estas oficinas se fundamentavam sob uma perspectiva de uma Educação Ambiental Crítica, como "práxis e processos dialógico, crítico, problematizador e transformador das condições objetivas e subjetivas que formam a realidade" (LOREIRO, 2006).

$\mathrm{Na}$ primeira oficina foi desenvolvido um jogo cooperativo, no qual peças eram colocadas sob um tabuleiro com uma paisagem de manguezal ao fundo, formando ao final uma nova paisagem, fruto da percepção coletiva do grupo (VASCONCELLOS, 2003). A paisagem inicial era composta com flora, fauna, entre outras características socioambientais. A medida que os alunos respondiam as questões propostas, eles recebiam pequenas figuras que complementavam aquela paisagam inicial. Estas figuras apresentavam características impactantes e degrantes ou não, de acordo com a reposta de cada pergunta. A figura inicial do manguezal, poderia se apresentar ao final com uma biota diferenciada, em situações degradantes como presença de lixo, esgoto doméstico, resíduos industriais, ou não.

As questões respondidas pelos alunos eram divididas em três temas gerais: Cartas de Saberes (incluindo temas como flora, fauna, características gerais de conhecimento acerca dos manguezais); Cartas de Ação (incluindo as escolhas que o jogador iria fazer para manter ou mudar uma situação que venha acontecer com o ambiente do manguezal); Cartas Socioambientais (incluindo temas que faziam o jogador questionar o que seria mais correto sob o olhar socioambiental e o que seria melhor para o futuro do manguezal e população do entorno). 
A oficina foi realizada nas turmas de $8^{\circ}$ e $7^{\circ}$ anos de uma escola municipal local. Nela, foi possível perceber que a maioria dos alunos identificou a paisagem como um manguezal. Segundo eles, as árvores, o aspecto da água, a umidade do solo, e o que muitos deles chamavam de "lama", foram algumas das características que fizeram identificar o mesmo. Foi interessante quando um dos alunos apontou de forma correta que os manguezais ficavam no entorno da Baía de Guanabara, e apesar de alguns deles fazerem uma ligeira confusão com os aspectos naturais, em linhas gerais eles identificaram bem a imagem do painel assim como as figuras pequenas.

Ao analisar os debates acerca das respostas para as perguntas, a maioria mostrou saber a importância dos manguezais. Eles afirmaram já ter visitado esse bioma, citando o manguezal de Mauá e o de Jardim Gramacho, embora este último sob um olhar negativo, os quais davam ênfase ao mangue daqueles locais como um lugar "sujo e com muito fedor".

Por fim, apesar da imagem final ser o reflexo da percepção coletiva, a possibilidade de análise e posterior transformação desta percepção era sugerida através da retirada de alguma peça, momento fundamental na atividade, visto que o manguezal é muita das vezes reconhecido como um ambiente "naturalmente degradado", trazendo assim a possibilidade da transformação a partir de práticas socioambientais que mudam este estado atual.

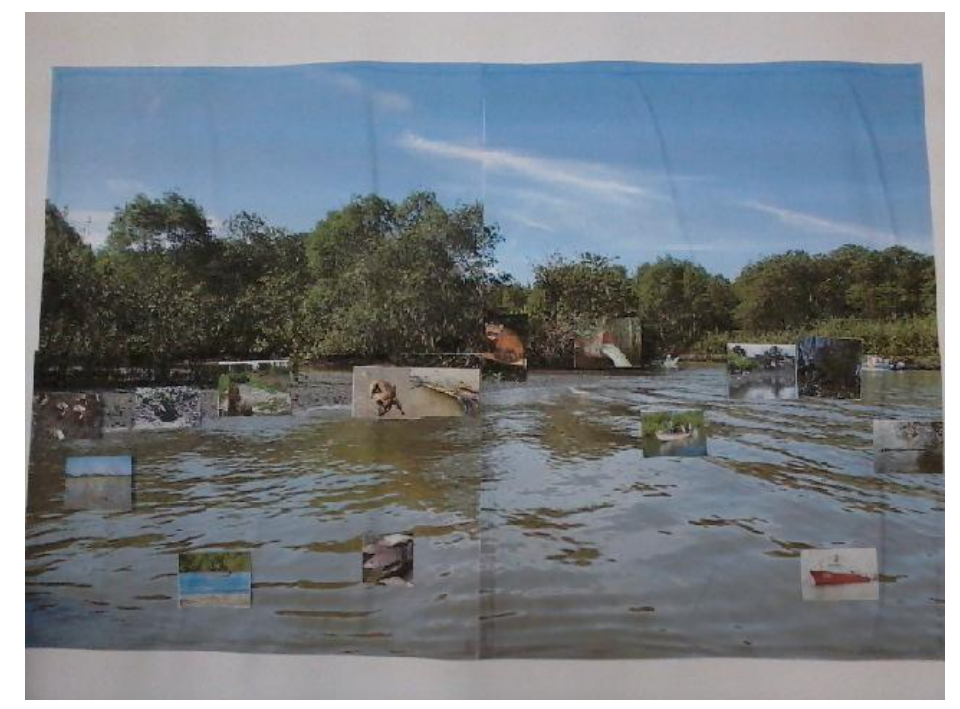

Figura 2: Paisagem final de um dos grupos com figuras adicionadas pelos alunos, dentre as quais umas são negativas como poluição e outras mais positivas como fauna e flora características.

Como resultado destas oficinas, no início de 2013 a BV Jovem já contava com uma aparência e estrutura, que aos poucos fora evoluindo de acordo com as necessidades que o site exigia, visto que, conforme explicitado anteriormente, a BV Jovem possui um público diferenciado da primeira Biblioteca Virtual. Após um período de levantamento de dados, pesquisas, criação, formatação e processo de finalização do site, a BV Jovem teve seu pré-lançamento marcado, com crianças reunidas pelo Projeto Alegria, projeto da FEBF, que trabalha com crianças das escolas do entorno de maneira interdisciplinar no espaço da universidade. 
Frente aos resultados obtidos na apresentação foi possível observar alguns pontos da BV Jovem que necessitavam de alguma reformulação, no qual refletimos em como se deve aplicar o conteúdo científico tornando o mesmo um espaço interativo e que contribua para o conhecimento do visitante, assim como organizar um banco de dados que possibilite traçar um perfil de usuário de cada uma das interfaces apresentadas.

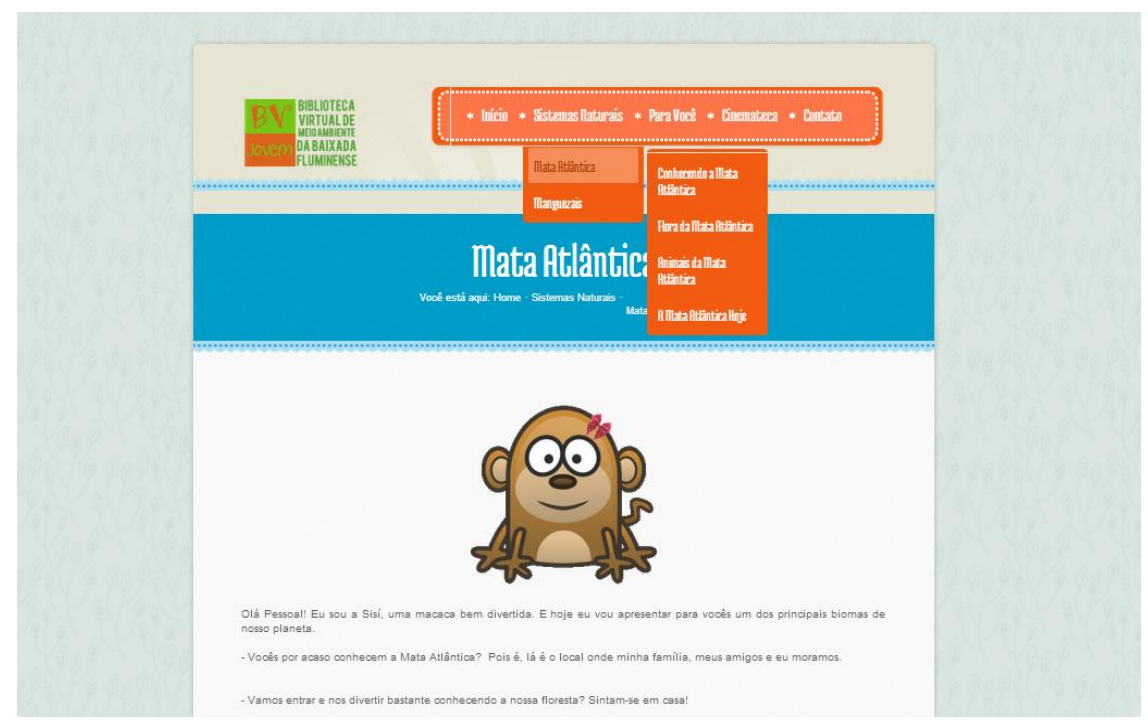

Figura 3: Página sobre o Bioma Mata Atlântica na versão atual da BV Jovem

\section{Considerações Finais}

Atualmente, a Biblioteca Virtual representa para a Baixada Fluminense, um espaço que além de alocar recursos educativos que abordam as questões socioambientais locais, disponibiliza de forma digital, mecanismos e informações ao professor para aperfeiçoar o uso de tecnologias em sala de aula como recursos didáticos num desenvolvimento de um ensino de Geografia de maneira mais crítica. O projeto, entretanto, continua em processo de construção, no qual está prevista uma nova fase de avaliação cujo objeto de análise é a praxis docente quanto ao uso de tecnologias educacionais e as análises do (re)significado quanto às metodologias pedagógicas do processo de formação do aluno.

Portanto, a preocupação de produzir materiais virtuais de aprendizagem e alocá-los num espaço pré-definido na internet, não é limitada. Para, além disto, busca-se efetivamente compreender as implicações sociais que a utilização de tecnologias educacionais traz para o ambiente educacional e, por conseguinte, contribuir efetivamente para uma aprendizagem significativa, de modo que a interação entre máquina (computador) e aluno possa resultar, de fato, em aprendizagem e aquisição de conhecimentos críticos acerca do espaço geográfico, no nosso caso, as tensões presentes no espaço da Baixada Fluminense.

Nesse sentido, reforçamos na relação entre Geografia e Ensino o importante papel da Biblioteca Virtual na socialização e aprendizagem acerca do espaço, uma vez que, acreditamos que ensinar Geografia de maneira crítica e eficiente precisa estar para além dos muros da escola. Ressaltamos ainda o papel do professor, neste caso o professor de Geografia, que precisa estar disposto a mobilizar os conceitos e categorias da Geografia 
fazendo a ponto com os instrumentos por ele utilizados, desde um mapa, o livro didático até, como apresentamos neste trabalho, meios digitais e diversos como a BV, permitindo assim Geografia mais dinâmica e crítica, fazendo com que seus alunos pensem e pratiquem em sua realidade o que aprendem a cada dia.

\section{Referências}

ACSELRAD, Henri; Pádua, José Augusto \& HERCULANO, Selene. Justiça Ambiental e Cidadania. Rio de Janeiro: Relume-Dumará, 2004.

ARENDT, H. A condição humana. 10ª ed., Forense Universitária: Rio de Janeiro, 2004.

BRAGA, Maria Cleonice Barbosa. Aprender e ensinar Geografia: a visão de egressos do Curso de Pedagogia da UEFS (Universidade Estadual de Feira de Santana). Tese (Doutorado) - Universidade Federal de São Carlos, 2006.

FADEL, S. Biblioteca Virtual do Meio Ambiente da Baixada Fluminense. In: Revista interagir: pensando a Extensão. Rio de Janeiro, n9, 220, janeiro a julho de 2006.

; SOUZA, G. L.; FERNANDES, J. D. P. Relações socioespaciais e conflitos revelados numa área de manguezais em Magé - Baixada Fluminense. In: Revista História, Natureza e Espaço. Rio de Janeiro: n.1 v. 1, 2012.

HABERMAS, J. Direito e democracia: entre factilidade e validade. Rio de Janeiro: Tempo Brasileiro, 1997, v.2, 352p.

KENSKI, V. M. Educação e tecnologias: o novo ritmo da informação. Campinas: Papirus, 2007.

LACERDA, L. D. Os manguezais do Brasil. In: VANNUCCI, Marta (org). Os manguezais e nós: uma síntese de percepções. São Paulo: Editora da Universidade de São Paulo, 2002, p. $193-205$.

LOUREIRO, C. F. B. Problematizando conceitos: contribuição à práxis em educação ambiental. In: LOUREIRO, C. F. B.; LAYRARGUES, P. P.; CASTRO, R. S. de (Orgs.). Pensamento complexo, dialética e educação ambiental. São Paulo, Cortez, 2006.

VASCONCELLOS, M. das M. N. Livro Jogo: Unidos para construir um mundo melhor. 1. ed. Rio de Janeiro: Gaia Comunicação, 2003. v. 1. 24p 